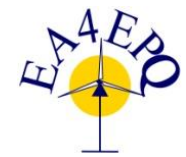

International Conference on Renewable Energies and Power Quality (ICREPQ'14)

Cordoba (Spain), $8^{\text {th }}$ to $10^{\text {th }}$ April, 2014

Renewable Energy and Pourer Qualily. Tournal (RE\&PQJ)

ISSN 2172-038 X, No.12, April 2014

\title{
Electric motors monitoring: An alternative to increase the efficiency of ball mills
}

\author{
M. G. Melero ${ }^{1}$, J. M. Cano ${ }^{1}$, J. Norniella ${ }^{1}$, F. Pedrayes ${ }^{1}$, M. F. Cabanas ${ }^{1}$, \\ C. H. Rojas ${ }^{1}$, G. Alonso ${ }^{1}$, J. M. Aguado ${ }^{2}$, and P. Ardura1 ${ }^{1}$ \\ ${ }^{1}$ Universidad de Oviedo, Dept. of Electrical Engineering \\ e-mail: melero@uniovi.es,jmcano@uniovi.es,jgnorniella@uniovi.es, pedrayesjoaquin@uniovi.es, \\ manes@uniovi.es, chrojas@uniovi.es,gonzalo@uniovi.es, ardurapablo@uniovi.es \\ ${ }^{2}$ Universidad de Oviedo, Dept. of Exploitation and Exploration of Mines \\ e-mail: maguado@uniovi.es
}

\begin{abstract}
Ball mills can be frequently found in ore grinding facilities. These machines show high energy consumption together with a low efficiency. As a consequence, even a small improvement on the performance of the grinding process can have a huge impact in the operating costs of the plant and in the optimization of energy resources. One of the reasons for this low efficiency rate is the difficulty of identifying the filing level, and as a consequence, the difficulty of operating the mill at the optimum filing condition. Through an extensive bibliographic review, this work attempts to reveal the interesting possibilities that motor monitoring techniques can have in improving the efficiency of ball mills
\end{abstract}

\section{Keywords}

Monitoring, electric motor, ball mill, efficiency.

\section{Introduction}

Mineral mills are machines used in those production processes which require the comminution of a certain material. The characteristics and operating principles of these mills can be very different, depending on the specific process and the target material; however, those known as ball mills are by far the most popular type (Figure 1).

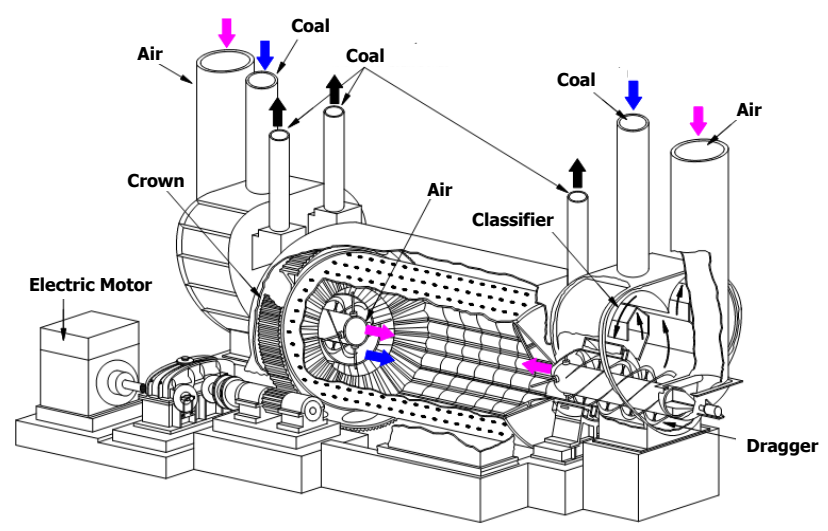

Fig. 1. Ball mill for a coal-fired power station.
Ball mills consist of a kind of rotating drum driven by an electric motor through a reduction gear. Inside of the drum the target material is arranged together with numerous steel balls (Figure 2), so that the comminution takes place due to the impacts and friction between those two components.

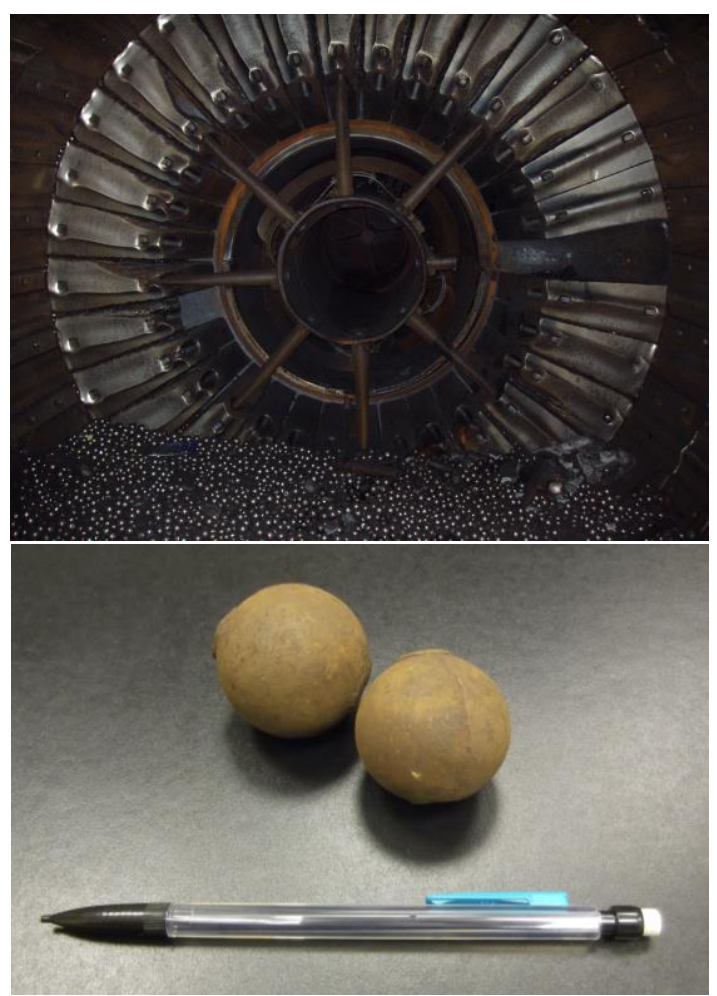

Fig. 2. Top: Inside view of the rotating drum of a coal mill showing the balls. Bottom: Detail of the balls

Despite its rudimentary operating principle, ball mills are the mineral grinding devices more widely spread [6], precisely because of their simplicity and robustness. Moreover, when the reduction ratio to be achieved in the ore grinding process is high, ball mills show a better 
performance than other comminution devices such as high pressure grinding rolls [6], [9]. For all these reasons, ball mills are popular equipment in ore processing facilities, coal-fired power stations and cement plants [10], [11].

Today, the grinding process that takes place in ball mills is far from being efficient. According to the conclusions of certain studies, less that $20 \%$ of the energy consumption of the process is actually employed in the comminution [1], [2]. This low efficiency can be even affected by two facts: the intrinsic difficulties in making an adequate sizing of the mill [3] and, specially, the troubles on bringing it to the optimum operation conditions [4].

Broadly speaking, the mineral grinding processes are characterized by high energy consumption: some studies estimate that between $3 \%$ and $4 \%$ of the total electricity consumed in the world [5]. In the case of a typical ore processing plant, this consumption can represent up to $70 \%$ of the energy required [5] and can even reach $75 \%$ in the case of cement plants [6], [7]. Lower values, but equally significant, can be found in the case of coal-fired power stations, where the coal grinding process may even reach between $20 \%$ and $25 \%$ of the energy consumed by the ancillary services of the plant [7], [8].

It can be deduced from the foregoing that, given the large power consumption figures involving ball mills, a small increase in efficiency in the grinding processes may have a large impact on the operating costs of the plant [12], as well as on the conservation and optimization of energy resources.

\section{Ball mills fill level monitoring}

One of the greatest research efforts in improving the efficiency of ball mills has focused on the monitoring of the fill level. For a given amount of steel balls, it is not desirable that the mill is too full or too empty of grinding material. If the fill level of ore grinding is low, most of the energy of the steel balls is wasted in impacts between them, leading to low comminution ratios. As the fill level increases, the gaps between the steel balls are being filled of grinding material and, as a consequence, the comminution ratio increases, reaching optimum values when all these voids are filled up. A fill level above this does not lead to an increment in the comminution ratio, due to the saturation of the collision areas. Finally, if the mill is overloaded, the grinding material causes a damping effect that decreases the comminution ratio. For these reasons, a proper monitoring of the fill level would allow operating the mill at maximum efficiency; however, as will be discussed below, this issue is still far from being solved.

The difficulty of determining the fill level of the mill is revealed by the complexity of the control of the grinding process, specifically in the case of the ball mill type [4], [13-15], [17], [19], [21]. Two factors contribute largely to this: the impossibility of siting sensors inside of the mill to provide halfway information between the input and output of the material [4], [13]; and the huge difficulty in obtaining an accurate mathematical modeling of the grinding process, which is strongly affected by the complexity of its dynamical characteristics (the movement of the material within the drum, the size distribution of the ore particles, jams of material, the rotating speed of the mill, etc.) [13], [14]-[18], [20]. As a consequence, existing techniques aiming to estimate the fill level of ball mills have been obtained experimentally.

The most straightforward way of controlling the load of a mill is the measurement of the power or current consumed by the electric motor that drives it. This procedure, quite simple to implement, faces the problem that the same energy consumption is observed with a low fill level or the optimum load. Above this fill level the energy consumption decreases, but this behavior makes this type of control unsuitable [22].

More traditionally used has been the procedure based on the measurement of the differential pressure between the inlet and outlet of the mill [23]. To apply this method an air flow through the mill is required, which can be used to avoid a powdery atmosphere or even to transport the material. As the fill level increases so does the differential pressure. However, this pressure is also affected by other factors such as the speed of the mill, the distribution of the particles according to their size, the mill lining system (shell plates and lifters), etc.

In recent years, there has been considerable research effort devoted to estimate the fill level of the ball mill from vibration measurement. The procedure is based on the intense mechanical vibration caused by the movement of the steel balls and the grinding material within the drum. The characteristics of the vibration are directly related to the operation mode of the mill and their particular design features [24]. Through successive analysis of the vibrations, this variable has been correlated with the fill level of the ball mill on different operating conditions [7], [24]-[27].

Apart from being an invasive technique that uses quite delicate sensors (accelerometers), the major drawback of this method, as it can be observed in [24], is that the vibration measurement shows a high sensitivity to the location of the accelerometers on the structure of the mill. This fact can condition the estimation of the fill level. In some cases attempts have been made trying to circumvent this problem by combining vibration measurement with acoustic measurements [7], [26], [28]; however, the procedure becomes more complex and the noisy conditions of operation of this type of machinery makes it difficult to draw firm conclusions [25].

Therefore, it can be concluded that with state of the art technology, determining the fill level of the mill cannot be done in a simple and precise way; i.e. without the need for complex algorithms or without monitoring mechanical variables through invasive techniques whose validity is subject to the measuring conditions. It makes sense then to carry on a deeper research effort in this topic, due to the high impact of an accurate estimation of the fill level on the efficiency of the mill, and the huge amount of energy involved in the grinding process 


\section{Electric motors monitoring}

The condition monitoring of electrical machines and the subsequent diagnosis has been for decades a matter of great interest to the industry. This is due to the fact that by foreseeing the best time for a required intervention in an electric machine, allows users to best schedule the maintenance tasks and avoid costly unexpected interruptions that, depending on the importance of the damaged machine can affect the whole plant.

Until the '80s, the monitoring techniques of electric machines were based almost exclusively on vibration measurement. By using these methods, mechanical malfunctions as misalignment and imbalance can be detected. In those years new techniques based on the measurement of electrical variables began to arise, not only for the detection of mechanical malfunctions but also electrical issues [29].

Today, motor condition monitoring has become a matter of the greatest importance in the protection systems for electric machines [30]. By applying these techniques, the reliability and availability can be significantly improved and the maintenance tasks simplified in a broad range of applications. Furthermore, the implementation of monitoring techniques in already installed machines does not generally require a high investment. Frequently, the sensors and hardware needed for this purpose are already available in the machine fulfilling protection functions, and all the necessary information can be obtain from them.

Motor current analysis is the most well-known technique within the field, especially for the case of squirrel cage induction motors. Motor current monitoring has many advantages over the conventional monitoring of vibrations, as it does not need additional sensors more than those used by the protection system of the machine. Furthermore, accelerometers are expensive and fragile devices that must be applied directly to the structure of the machine. Specifically, motor current monitoring can detect the presence of broken rotor bars [31]-[44], stator insulation failures [45]-[52] and mechanical malfunctions [53]-[58].

An interesting phenomenon takes place when applying current monitoring diagnosis to a motor that is driving a load that shows a resistant torque with pulsating or oscillatory character. In these cases, an oscillation of mechanical nature determines the appearance of harmonics in the supply current and the instantaneous electrical power absorbed by the machine [41], [59]-[64]. If this harmonics show up at those frequencies used to characterized motor failures, the diagnosis method can lead to a false fault indication. The most important issue for the present case is that the pulsating torque of the load causes changes in the current spectrum at frequencies that are directly related with the load disturbances. This indicates that these changes can be detected from variations in the current or instantaneous power spectrums. In fact, in [65] a method is proposed for the monitoring of vibrations based on the current measurement.
Similarly, another interesting phenomenon that occurs in the monitoring of the current is derived from the inertia of the motor-load pair. As noted in [66]-[69], the inertia is a factor that greatly influences the amplitude of the harmonics associated with the oscillatory torque linked to rotor failures. This is a good evidence of the ability to detect variations of the inertia through the spectral analysis of motor currents. Figure 3 shows the evolution of the harmonics associated to rotor asymmetry ( $1 \pm 2 s f)$, together with an oscillating torque at frequency $2 s f(s$ being the slip of the induction motor and $f$ the frequency of the supply grid).

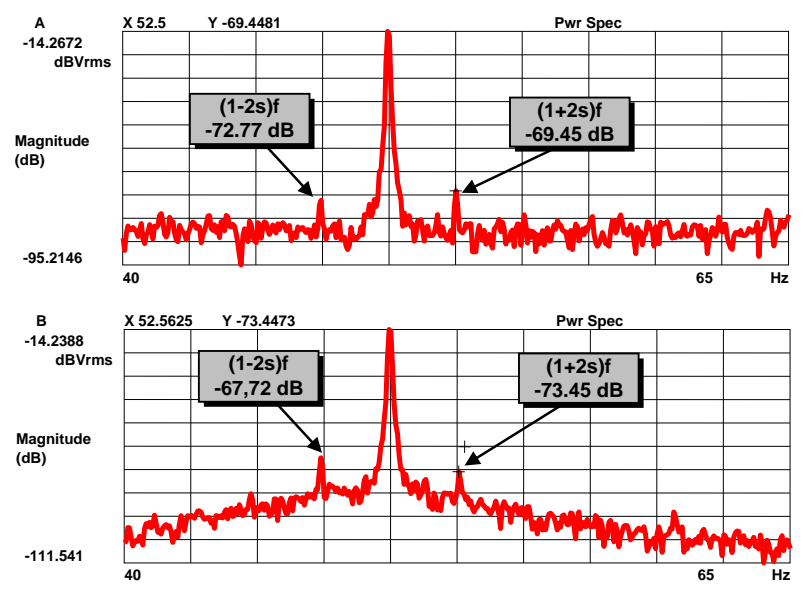

Fig. 3. Current spectra of an induction motor showing the harmonics associated to a rotor asymmetry without a flywheel (top) and with a flywheel (bottom).

\section{Monitoring the ball mill through the electric motor drive}

Several aspects are characteristic in the case of ball mills. They are devices greatly affected by vibrations, insomuch that the latest methods for detecting the fill level are based on the spectral analysis of these parameters. They are also devices with a large moment of inertia, due to the huge amount of mass inside and also to the distribution of this mass far from the rotating axis. Finally, ball mills are often coupled to the motor through a reduction gear. This device causes pulsating torques linked to the gear frequency that entails the corresponding harmonic frequencies in the current spectrum. Figure 4 shows this phenomenon for the case of the current spectrum of a motor driving a coal ball mill. Sidebands around the fundamental frequency and related with the gear frequency can be observed.

All the previous considerations open really promising research possibilities on the field of monitoring the fill level of ball mills. These new methods will use the evolution of specific harmonics of the motor current spectrum (or the instantaneous power, alternatively) with the variations of the inertia and the vibration caused by changes in the amount of grinding material. These aspects can be studied from monitoring the electric variables of the motor. 


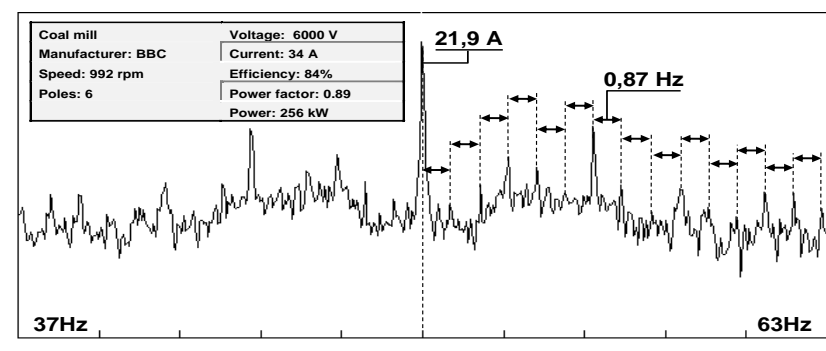

Fig. 4. Current spectrum of a motor driving a coal ball mill from a coal-fired power station.

Finally, it can be said that the relationship between the operating conditions of the mill and the electrical variables of the motor is obvious. Therefore, the development of a method for the monitoring of the machine based on the analysis of the supply current (or the instantaneous power demand) of the electric motor that drives the ball mill has to be considered as a promising alternative to address the problem of estimating the fill level of the device. An accurate assessment of this parameter would lead to an immediate increase of the energy efficiency of this type of equipment.

\section{Conclusion}

The main conclusions that can be drawn from the discussion presented in this work are the following:

Ball mills are machines that show large electric energy consumptions and low efficiencies; therefore even a small improvement in the milling processes may have a large impact on the operating costs of the plant and in the optimization of the energy resources.

State of the art techniques do not allow the determination of the filling level of ball mills in a precise manner, which negatively impacts their performance. They need to resort to the monitoring of mechanical variables whose usefulness is subject to the conditions under which these measurements are made.

Numerous studies, carried out on the monitoring of electrical machines by tracking their operating electrical signals, allow observing the influence of parameters such as the inertia or the presence of gears on this variables. Since ball mills are machines where these issues concur, a clear relationship between the operating conditions of this machinery and the electrical variables of the motor that drives it can be established. Therefore, the development of a method for the monitoring of the fill level of the mill, based on the analysis of the supply current of the electric motor or its instantaneous power demand, is a promising alternative to be considered in order to improve the energy efficiency of this equipment.

\section{Acknowledgement}

This work was supported in part by the Spanish Research, Development and Innovation Program under Grant DPI2011-26535. The authors also wish to acknowledge the support provided by the University of Oviedo in the development of this work.

\section{References}

[1] D. W. Fuerstenau, P. C. Kapur, K. Schönert, and M. Marktsheffel, "Comparison of energy consumption in the breakage of single particles in rigidly mounted roll mill with ball mill grinding," Int. J. Miner. Process. 28, pp. 109-125, 1990,

[2] O. Labahn and B. Kohlhaas, Cement Engineers' Handbook. Bauverlag, 1983, pp. 239-241.

[3] C. Arentzen and R. Bhappu, "High efficiency ball mill grinding," Engineering and Mining Journal, April 2008, pp. $62-68$

[4] M. Boulvin, A. V. Wouwer, R. Lepore, C. Renotte, and M. Remy, "Modeling and control of cement grinding processes," IEEE Trans. Control Syst. Technol., vol. 11, no. 5, pp. 715-725, Sep. 2003.

[5] National Materials Advisory Board, Comminution and Energy Consumption, Publication NMAB-364, National Academy Press, Washington, DC, 1981, 283 pp.

[6] D. W. Fuerstenau, J. J. Lutch, A. De, "The effect of ball size on the energy efficiency of hybrid high-pressure roll mill/ball mill grinding," Powder Technology, 105, pp. 199-204, 1999.

[7] G. Si , H. Cao, Y. Zhang, L. Jia, "Experimental investigation of load behaviour of an industrial scale tumbling mill using noise and vibration signature techniques," Minerals Engineering, 22, pp. 1289-1298, 2009.

[8] P. Huang, M. Jia, B. Zhong, "A study on the technique of measuring the fill level based on the vibration signal of the ball mill shell," in Proc. 2009 WRI World Congress on Computer Science and Information Engineering, vol. 6, pp. 202 - 206, 2009.

[9] M. von Seebach and L. Schneider, "Update on finish grinding with improved energy efficiency," IEEE Trans. Ind. Appl., vol. IA-23, no. 3, May/June 1987.

[10] R. A. Errath, "15 000-HP gearless ball mill drive in cement-why not!," IEEE Trans. Ind. Appl., vol. 32, no. 3, pp. 663-669, May/June 1996.

[11] J. R. Rodríguez, J. Pontt, P. Newman, R. Musalem, H. Miranda, L. Morán, and G. Alzamora, "Technical evaluation and practical experience of high-power grinding mill drives in mining applications," IEEE Trans. Ind. Appl., vol. 41, no. 3, pp. 866 - 874, May/June 2005.

[12] J. M. Aguado, A. L. Coello, O. N. Tijonov, and M. A. Rodríguez, "Implementation of energy sustainability concepts during the comminution process of the Punta Gorda nickel ore plant (Cuba)," Powder Technology, 170, pp. 153-157, 2006.

[13] J. Wei, J. Wang, and S. Guo, "Mathematic modeling and condition monitoring of power station tube-ball mill systems," in Proc. 2009 American Control Conference, 2009

[14] X. Chen, J. Zhai, Q. Li, and S. Fei, "Fuzzy logic based online efficiency optimization control of a ball mill grinding circuit," in Proc. Fourth International Conference on Fuzzy Systems and Knowledge Discovery, FSKD 2007, vol. 2, pp. $575-580,2007$.

[15] J. Sue, X. Zhang, X. Zeng, and Y. Cui, "Design and Simulation of Robust Ball Grinding Mill Control System," in Proc. Chinese Control and Decision Conference, 2009. CCDC '09, pp. 2813 - 2818, 2009.

[16] J. L. Salazar, L. Magne, G. Acuña, and F. Cubillos, "Dynamic modelling and simulation of semi-autogenous mills," Minerals Engineering, 22, pp.70-77, 2009. 
[17] X. Chen, S. Li, J. Zhai, and Q. Li, "Expert system based adaptive dynamic matrix control for ball mil grinding circuit," Expert Systems with Applications, 36, pp. 716-723, 2009.

[18] H. Benzer, "Modeling and simulation of a fully air swept ball mill in a raw material grinding circuit," Powder Technology, 150, pp. 145-154, 2005.

[19] P. Zhou, T. Chai, H. Wang, and Ch. Su, "Multivariable Decoupling Internal Model Control for Grinding Circuit," 2008 American Control Conference, 2008.

[20] H. J. C. Gommeren, D. A. Heitzmann, J.A.C. Moolenaar, and B. Scarlett, "Modelling and control of a jet mill plant," Powder Technology, 108, pp. 147-154, 2000.

[21] W. Heng and J. Minping, "A fuzzy control method for ball mill system based on fill level soft sensor," Chinese Control and Decision Conference, CCDC '09, pp. 5888 - 5891, 2009.

[22] J. Kolacz, "Measurement system of the mill charge in grinding ball mill circuits," Minerals Engineering, vol.10, no.12, pp. 1329-1338, 1997.

[23] J. Kolacz; Control of the mill charge behavior in dry tumbling mills, Minerals Engineering, vol.12, no.1, pp.5164, 1999.

[24] B. Behera, B. K. Mishra, and C. V. R. Murty, "Experimental analysis of charge dynamics in tumbling mills by vibration signature technique," Minerals Engineering, 20, pp. 84-91, 2007.

[25] Z. Su, P. Wang, X. Yu, and Zhen-zhong, "Experimental investigation of vibration signal of an industrial tubular ball mill: Monitoring and diagnosing," Minerals Engineering, 21, pp. 699-710, 2008.

[26] G. Si, H. Cao, Y. Zang, and L. Jia, "A new approach to load measurement for industrial scale mill," in Proc. of 2008 IEEE International Conference on Mechatronics and Automation, 2008.

[27] P. Huang, M. Jia, and B. Zhong, "A study on the technique of measuring the fill level based on the vibration signal of the ball mill shell," in Proc. 2009 World Congress on Computer Science and Information Engineering, 2009.

[28] P. R. Aguiar, P. J. A. Serni, E. C. Bianchi, and F. R. L. Dotto, "In-process grinding monitoring by acoustic emission," in Proc. IEEE International Conference on Acoustics, Speech, and Signal Processing, ICASSP '04, vol. 5, pp. 405-408, 2004.

[29] P. J. Tavner and J. Penman, Condition Monitoring of Electrical Machines. Letchworth, U.K.: Research Studies Press, 1987.

[30] P. Vas, Parameter Estimation, Condition Monitoring, and Diagnosis of Electrical Machines, Oxford University Press, 1993.

[31] W. Deleroi, "Squirrel cage motor with broken bar in rotor,physical phenomena and their experimental assessment," in Proc. International Conference on Electrical Machines, vol. 2, pp.767-771, 1982.

[32] G. Kliman and V. Koegl, "Non invasive detection of broken rotor bars in operating induction machines," IEEE Trans. Energy Convers., vol. 3, no. 4, Dec. 1988.

[33] N. Elkasagby, R. Eastham, and G.Dawson, "Detection of broken bars in the cage rotor on an induction machine," IEEE Trans. Ind. Appl., vol. 28, no. 1, Jan./Feb. 1992.

[34] A. Bellini, "Quantitative evaluation of induction motor broken bars by means of electrical signature analysis," in Proc. 35 th IAS Annual Meeting and World Conference on Industrial Applications of Electrical Energy, 2000.

[35] A. Bellini, F. Filipetti, G. Franceschini, and G. Tasoni, "Enels experience with on-line diagnosis of large induction motor cage failures," in Proc. $35^{\text {th }}$ IAS Annual Meeting and World Conference on Industrial Applications of Electrical Energy, 2000.
[36] R. Schoen and H. Teo, "A new method of current-based condition monitoring in induction machines operating under arbitrary load conditions," in Proc, Int. Conference on Electric Machines, ICEM'94, vol. 2, 1994.

[37] M. F. Cabanas et al., "A new methodology for applying the FFT to induction motor diagnosis" in Proc. The 1999 IEEE International Symposium on Diagnostics for Electrical Machines, Power Electronics and Drives SDEMPED'99, 1999.

[38] S. Cruz and A. Cardoso, "Further developments on the use of the synchronous reference frame current Park's vector approach," in Proc. of The IEEE International Symposium on Diagnostics for Electrical Machines, Power Electronics and Drives IEEE SDEMPED 01, 2001.

[39] H. Douglas, P. Pillay, and A. Ziriani, "A new algorithm for transient motor current signature analysis using wavelets," IEEE Trans. Ind. Appl, vol. 40, no. 5, pp. 1361-1368, 2004.

[40] F. Briz, M. Degner, P. Garcia, and D. Bragado, "Broken rotor bar detection in line-fed induction machines using complex wavelet analysis of start up transients," in Conference Record of the 2007 IEEE Industry Applications Conference, 2007. 42 ${ }^{\text {nd }}$ IAS Annual Meeting, pp. 2254 $2261,2007$.

[41] M. Cabanas, F. Pedrayes, R. Gonzalez, M. Melero, G. Orcajo, J. Cano, and C. Rojas, "A new on-line method for the early detection of broken rotor bars in asynchronous motors working under arbitrary load conditions," in Conference Record of the 2005 IEEE Industry Applications Conference, 2005. 40nd IAS Annual Meeting, 2005.

[42] J. Antonino-Daviu, M. Riera-Guasp, J. Folch, and M. Palomares, "Validation of a new method for the diagnosis of rotor bar failures via Wavelet transform in industrial induction machines," IEEE Trans. Ind. Appl., vol. 42, no. 4, pp. 990-996, Jul./Aug. 2006.

[43] M. Riera-Guasp, J. Antonino-Daviu, J. Folch, and M. Molina, "The use of the wavelet approximation signal as a tool for the diagnosis of Rotor bar failures," IEEE Trans. Ind. Appl., vol. 44, no.3, pp. 716-726, 2008.

[44] Y. S. Gennadi, S.-A. Ahmed, C.-C. Yeh, and A. Demerdash, "Analysis and diagnostics of adjacent and non adjacent broken-rotor-bar faults in squirrel-cage induction machines," IEEE Trans. Ind. Electron., vol. 56, no. 11, Nov. 2009.

[45] M. G. Melero, L. A. R. Villalba, M. F. Cabanas, G. A. Orcajo, and J. M. Cano, "A maintenance, protection and control system for asynchronous motors based on PLC," in Proc. IEEE Sdemped'97 - International Symposium on Diagnostics for Electrical Machines, Power Electronics and Drives, 1997.

[46] A. Stavrou, H. G. Sedding, and J. Penman, "Current monitoring for detecting inter-turn short circuits in induction motors," IEEE Trans. Energy Convers., vol. 16, no. 1 , Mar. 2001

[47] A. J. M. Cardoso, S. M. A. Cruz, and D. S. B. Fonseca, "Inter-turn stator winding fault diagnosis in three-phase induction motors, by Park's vector approach", IEEE Trans. Energy Convers., vol. 14, Sep. 1999.

[48] S. M. A. Cruz and A. J. M. Cardoso, "Stator winding fault diagnosis in three-phase synchronous and asynchronous motors, by the extended Park's vector approach", IEEE Trans. Ind. Appl., vol. 37, no. 5, Sep./Oct. 2001.

[49] J. Sottile and J.L. Kohler, "An on-line method to detect incipient failure of turn insulation in random-wound motors". IEEE Trans. Energy Convers., vol. 8, no. 4, Dec.1993.

[50] M. G. Melero, M. F. Cabanas, C. H. Rojas, G. A. Orcajo, J. M. Cano, G. A. Capolino, and H. Henao, "Système pour la détection de défauts d'isolement dans les moteurs à 
induction," Revue Internationale de Génie Electrique, vol. 5, no.1, pp. 49-61, Mar. 2002.

[51] J. L. Kohler, J. Sottile and F. C. Trutt, "Condition monitoring of stator windings in induction motors: Part I-Experimental investigation of the effective negativesequence impedance detector". IEEE Trans. Ind. Appl., vol. 38, no. 5, Sep./Oct. 2002.

[52] M. G. Melero, M. F. Cabanas, C. Rojas, G. A. Orcajo, J. M. Cano, and J. Solares, "Study of an induction motor working under stator winding inter-turn short circuit condition," in Proc. Symposium on Diagnostics for Electric Machines, Power Electronics and Drives SDEMPED 2003, 2003.

[53] F. Faya, M. F. Cabanas, M. G. Melero, and C. H. Rojas, "Rolling elements bearing damage detection by means of current and airgap torque analysis," in Proc. of International Conference on Electrical Machines (ICEM'98), 1998.

[54] M. F. Cabanas, M. G. Melero, J. Gómez, and J. Solares, "Shaft misalignment diagnosis of induction motors using current spectral analisys: a theoretical approach," in Proc. of International Conference on Electrical Machines (ICEM'96), 1996.

[55] M. F. Cabanas, M. G. Muñiz, M. G. Melero, and J. Gómez, "Effects of shaft misalignment on the current spectrum of induction motors," in Proc. Fifth International Conference Modelling and Simulation of Electrical Machines, Converters and Systems (ELECTRIMACS '96), 1996.

[56] R. R. Schoen, T. G. Habetler, F. Kamran, and R. G. Bartfield, "Motor bearing damage detection using stator current monitoring," IEEE Trans. Ind. Appl., vol. 31, no. 6, pp. 1274-1279, Nov./Dec. 1995.

[57] J. R. Stack, T. G. Habetler, and R. G. Harley, "Faultsignature modeling and detection of inner-race bearing faults," IEEE Trans. Ind. Appl., vol. 42, no. 1, pp. 61-68, Jan./Feb. 2006.

[58] A. Ibrahim, M. El Badaoui, F. Guillet, and W. Youssef, "Electrical signals analysis of an asynchronous motor for bearing fault detection," in Proc. of IEEE IECON 2006, Nov. 2006, pp. 4975-4980.

[59] R. R. Schoen and T. G. Habetler, "Effects of time-varying loads on rotor fault detection in induction machines," IEEE Trans. Ind. Appl., vol. 31, no. 4, Jul./Aug. 1995.

[60] R. R. Schoen and T. G. Habetler, "Evaluation and implementation of a system to eliminate arbitrary load effects in current-based monitoring of induction machines," IEEE Trans. Ind. Appl., vol. 33, no. 6, Nov./Dec. 1997.
[61] J. E. McInroy and S. F. Legowski, "Using power measurements to diagnose degradations in motor drivepower systems: a case study of oilfield pump jacks," IEEE Trans. Ind. Appl., vol. 37, no. 6, Nov./Dec. 2001.

[62] C. Linest and P. Warner, "Electrical power flow spectral analysis relating to vibration in a large electromechanical system," in Proc. IEEE PES PowerAfrica 2007 Conference and Exposition.

[63] A. Trzynadlowski and E. Ritchie, "Comparative investigation of diagnostic media for induction motors: A case of rotor cage faults," IEEE Trans. Ind. Electron., vol. 47, no. 5, pp. 1092-1099, Oct. 2000.

[64] S. Legowski, A. S. Ula, and A. Trzynadlowski, "Instantaneous power as a medium for the signature analysis of induction motors," IEEE Trans. Ind. Appl., vol. 32, no. 4, pp. 904-909, Jul./Aug. 1996.

[65] C. M. Riley, B. K. Lin, T. G. Habetler, and R. R. Schoen, "A method for sensorless on-line vibration monitoring of induction machines," IEEE Trans. Ind. Appl., vol. 34, no. 6, Nov./Dec. 1998

[66] F. Filippetti, G. Franceschini, C. Tassoni, and P. Vas, "AI techniques in induction machine diagnositics including the speed ripple effect," in Proc. Conf. IEEE IAS Annu. Meeting, 1996, pp. 655-662.

[67] F. Filippetti, G. Franceschini, C. Tassoni, and P. Vas, "Impact of speed riple on rotor fault diagnosis of induction machines," in Proc. Int. Conf. Elect. Mach. (ICEM'96), 1996, pp. 452-457.

[68] C. Kral, F. Pirker, and G. Pascoli, "Influence of inertia on general effects of faulty rotor bars and the Vienna Monitoring Method," in Proc. IEEE Int. Symp. Diag. Elect. Mach., Power Electron. Drives (SDEMPED'01), 2001, pp. 447-452.

[69] C. Kral, F. Pirker, and G. Pascoli, "The impact of inertia on rotor fault effects - theoretical aspects of the Vienna monitoring method," IEEE Trans. Power Electron., vol. 23, No. 4, pp. 2136-2142, 2008.

[70] J. Pontt, W. Valderrarna, L. Magne, G. Sepúlveda, and P. Espinoza, "New Method for Detection of Harmful Impacts on Shell Liners in Large Grinding Mills," in Proc, IMTC 2004 - Instrumentation and Measurement Technology Conference". 